\title{
Article
}

\section{Catalytic Activity Control via Crossover between Two Different Microstructures}

Yuheng Zhou, Yihan Zhu, Zhi-Qiang Wang, Shihui Zou, Guicen Ma, Ming Xia, Xueqian Kong, Liping Xiao, Xue-Qing Gong, and Jie Fan

J. Am. Chem. Soc., Just Accepted Manuscript • DOI: 10.1021/jacs.7b05476 • Publication Date (Web): 08 Sep 2017

Downloaded from http://pubs.acs.org on September 12, 2017

\section{Just Accepted}

"Just Accepted" manuscripts have been peer-reviewed and accepted for publication. They are posted online prior to technical editing, formatting for publication and author proofing. The American Chemical Society provides "Just Accepted" as a free service to the research community to expedite the dissemination of scientific material as soon as possible after acceptance. "Just Accepted" manuscripts appear in full in PDF format accompanied by an HTML abstract. "Just Accepted" manuscripts have been fully peer reviewed, but should not be considered the official version of record. They are accessible to all readers and citable by the Digital Object Identifier (DOI®). "Just Accepted" is an optional service offered to authors. Therefore, the "Just Accepted" Web site may not include all articles that will be published in the journal. After a manuscript is technically edited and formatted, it will be removed from the "Just Accepted" Web site and published as an ASAP article. Note that technical editing may introduce minor changes to the manuscript text and/or graphics which could affect content, and all legal disclaimers and ethical guidelines that apply to the journal pertain. ACS cannot be held responsible for errors or consequences arising from the use of information contained in these "Just Accepted" manuscripts. 


\section{INTRODUCTION}

Nanometer-sized gold particles have attracted great fundamental research interests due to their diverse structures and fascinating catalytic properties ${ }^{1-3}$. Despite their identical face-centered cubic (f.c.c.) atomic packing pattern, the catalytic activities are highly sensitive to the non-periodic structural features, such as crystal facets, grain/domain boundaries and defects ${ }^{4}$. Actually, most studies indicate that only a small fraction of the total metallic sites on a gold nanoparticle frequently contributes to its catalytic activity ${ }^{5}$. For example, the low coordinated perimeter ${ }^{6}$ and corner sites of gold nanopartilces ${ }^{7}$ have been reported to exhibit extremely high catalytic activity. On the other side, gold nanostructures in the form of MTP consist of f.c.c. structured tetrahedra joined by twin boundaries with elastic strain to give decahedra or icosahedra $^{8-10}$. Such MTPs are rich in twin boundaries exposed with high-index $\{211\}$-like facets ${ }^{11}$, along with a high probability of stacking faults (SFs) in the vicinity of the (111) coherent twin boundaries (TBs) due to the low SF energy $^{12}$, and thus exhibit very different properties with respect to their single-crystals counterparts ${ }^{13}$. It is interesting to note that in some cases, the presence of twin defects (i.e. TBs and SFs) imposes a stronger impact on the catalytic activity than the type of facet ${ }^{11}$. For instant, Choi et al. investigated the catalytic formic acid oxidation activities of Pd nanocrystals with different shapes and twin structures and revealed that both decahedra and icosahedra exhibited higher specific activities than cubes even though the $\{111\}$ facets were less active than the $\{100\}$ facets ${ }^{11}$. Wang et al. compared the catalytic activities of $\mathrm{Au}_{75} \mathrm{Pd}_{25}$ icosahedrons and octahedrons for the aerobic oxidation of cyclohexane and demonstrated that twins in icosahedrons predominately generated tensile surface structure and highly negatively charged surface, which could enhance the catalytic activity ${ }^{14}$. However, in both cases, the structure-activity correlation is mainly supported by theoretical calculations while clear experimental evidence is rarely reported. A comprehensive understanding of the twin effect on catalysis is yet implemented due to the plagued composition and facet effect as well as the poorly controlled twin structures.

Different from their single-crystalline counterparts, the growth of nanoparticles that contain twin defects can be quite difficult to control because multiple competitive growth pathways can evolve such structures ${ }^{15}$. In traditional bottom-up approaches, the twin defects of nanoparticles are tuned by various experimental parameters including type of seeds, stabilizers, additives, solvent, and temperatures, following a "nucleation and growth" or "seeded growth" mechanism ${ }^{16,17}$. The complex mechanism makes it difficult to rationally and reproducibly manipulate the process and thus the populations of MTP and SC. Besides, uncertainty in the loading process could also affect the catalytic performance and thus hinders the investigation of twin effects. 
Here we report a simple post-synthesis method to manipulate the populations of MTP versus SC of AuNPs. We find that the water treatment leads to a drastic structural change from MTP to SC, which significantly reduces the proportion of MTP (from $86 \%$ to $26 \%$ ). Meanwhile, the binding with thiols in non-polar solvent results in a reverse SC-to-MTP conversion of AuNPs. The crossover of these two microstructures allows a facile control over the defects associated with the twin boundaries of AuNPs, and helps us to reveal the importance of twin boundary effects on gas-phase catalytic oxidation of alcohols. Kinetic studies indicate that the chemisorption of alcohols on MTP is significantly stronger than that on SC, which is further confirmed by temperature-programmed desorption (TPD) and solid state nuclear magnetic resonance (NMR) measurements. This simple solvent posttreatment method has also been validated to improve the catalytic performance of other supported gold catalysts for the oxidation of alcohols by tuning their microstructures.

\section{EXPERIMENTAL SECTION}

\subsection{Materials synthesis}

Synthesis of AuNPs. The synthesis of AuNPs is similar to the method reported by Zheng et $\mathrm{al}^{18}$. In a typical synthesis, $100 \mathrm{mg}$ of $\mathrm{AuPPh}_{3} \mathrm{Cl}$ was mixed with $400 \mu \mathrm{L}$ of dodecanethiol in $20 \mathrm{~mL}$ of benzene to form a clear solution. Then, $84 \mathrm{mg}$ of $\mathrm{NaBH}_{4}$ was added into the solution in one portion. The mixture was heated at $55{ }^{\circ} \mathrm{C}$ for $7 \mathrm{~h}$ before it was cooled down to the room temperature. AuNPs were precipitated out from the reaction mixture as black solid powder by addition of 20 $\mathrm{mL}$ of ethanol. The products were separated by centrifugation and washed serveral times with ethanol. The size of AuNPs is $3.3 \pm 0.5 \mathrm{~nm}$ as determined by TEM.

Synthesis of silica microspheres. Silica microspheres were synthesized by a classic Stöber method ${ }^{19}$. Typically, $3.14 \mathrm{~mL}$ of ammonia water $(25 \%)$ was mixed with $80 \mathrm{~mL}$ of ethanol (containing $5 \mathrm{~mL}$ of water), followed by vigorously stirring for $30 \mathrm{~min}$ at $25{ }^{\circ} \mathrm{C}$. Subsequently, 6 $\mathrm{mL}$ of tetraethyl orthosilicate was added to this solution. The mixture was stirred vigorously for $1 \mathrm{~h}$ and was then filtered and dried at room temperature. The particle size is $\sim 100 \mathrm{~nm}$ as determined by TEM.

Synthesis of $0.5 \mathbf{w t} \% \mathbf{A u} / \mathrm{SiO}_{2}$. AuNPs were loaded on the silica microspheres by a colloid deposition method as previously reported ${ }^{20}$. Typically, 5.0 mg of AuNPs were dissolved in $25 \mathrm{~mL}$ of chloroform or toluene at $25{ }^{\circ} \mathrm{C}$, followed by the addition of $1.0 \mathrm{~g}$ of silica microspheres. After $30 \mathrm{~min}$ stirring, the solid product was collected by centrifugation and dried in air. The loading efficiency is more than $99 \%$ as determined by inductively coupled plasma-mass spectroscopy (ICP-MS). The as-synthesized $\mathrm{Au} / \mathrm{SiO}_{2}$ was calcined at $350{ }^{\circ} \mathrm{C}$ for 5 h to remove surface capping agents before using in post-treatment processes and catalytic reactions.

Post-treatment process for $\mathbf{A u} / \mathrm{SiO}_{2}$. Generally, 50 mg of $\mathrm{Au} / \mathrm{SiO}_{2}$ samples were washed 3 times with $2 \mathrm{~mL}$ of the desired solvent (e.g. water, methanol, ethanol, chloroform and toluene) and centrifuged at $10000 \mathrm{rmp}$ for $5 \mathrm{~min}$, followed by drying and annealing at $350{ }^{\circ} \mathrm{C}$ for $5 \mathrm{~h}$.

Process of thiol/toluene treatment. In a typical treatment process, $\mathrm{Au} / \mathrm{SiO}_{2}$ catalysts (200 mg) were soaked in $5 \mathrm{~mL}$ of toluene containing $50 \mu \mathrm{L}$ of dodecanethiol for $3 \mathrm{~h}$ at $60{ }^{\circ} \mathrm{C}$ and centrifuged at 10000 rmp for $5 \mathrm{~min}$, followed by drying and annealing at $350{ }^{\circ} \mathrm{C}$ for $5 \mathrm{~h}$. For treatment of toluene, no thiol was added.

\subsection{Characterization}

Wide-angle X-ray diffraction (XRD) patterns were recorded on a Rigaku Ultimate IV diffractometer using $\mathrm{CuK} \alpha$ radiation $\left(40 \mathrm{kV}, 40 \mathrm{~mA}, 5^{\circ} \mathrm{min}^{-1}\right.$ from 30 to $\left.5^{\circ}\right)$. Transmission electron microscopy (TEM) images were recorded on the Tecnai G2 F2o S-TWIN transmission electron microscope, operating at $200 \mathrm{kV}$. X-ray photoelectron spectroscopy (XPS) was performed in a VG Scientific ESCALAB Mark II spectrometer. All binding energies were referenced to the Cis peak at $284.8 \mathrm{eV}$ of the surface adventitious carbon to correct the shift caused by charge effect. ICP-MS was performed on a PerknElmer NexION 30oXX spectrometer. In-situ heating experiment was carried out on a FEI Titan S-Twin transmission electron microscope working at $300 \mathrm{kV}$ using a Gatan 628 single tilt heating holder. Solid-state NMR spectroscopy was carried out on a Bruker Avance HD III 9.4 T spectrometer with a $3.2 \mathrm{~mm}$ triple-channel probe. The ${ }^{1} \mathrm{H}$ and ${ }^{13} \mathrm{C}$ signal resonances are at $400.13 \mathrm{MHz}$ and $100.62 \mathrm{MHz}$, respectively. The chemical shifts of ${ }^{13} \mathrm{C}$ were referenced to adamantane at $38.5 \mathrm{ppm}$.

\subsection{Catalytic Reaction}

The gas-phase oxidation of benzyl alcohol (n-hexanol, n-heptanol, n-octanol) was carried out in a fixed bed vertical glass reactor $(\mathrm{h}=250 \mathrm{~mm}, \mathrm{~d}=12 \mathrm{~mm})$, fitted with a glass frit carrying the catalyst (20 mg for $0.5 \mathrm{wt} \% \mathrm{Au} / \mathrm{SiO}_{2}$ ) and provided with an electronically controlled furnace.

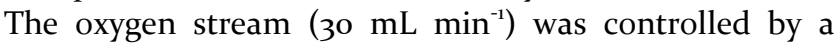
mass flow instrument and the liquid reagent $\left(1.8 \mathrm{~mL} \mathrm{~h}^{-1}\right)$ was supplied through a syringe pump. Liquid vaporization occurred on the reactor wall prior to the catalytic bed. The tests were performed at $220{ }^{\circ} \mathrm{C}$. The products were accumulated for every hour and analyzed by gas chromatography (GC). The selectivity was calculated as mol of produced benzaldehyde per mol of reacted benzyl alcohol. The carbon balance was $>99 \%$ in the case of selectivity near $99 \%$. The similar activities for catalysts with different masses under the same contact time suggest that the diffusion effect has been eliminated in these catalytic tests.

\subsection{Partial pressure experiments}

The partial pressure experiment was carried out at $240{ }^{\circ} \mathrm{C}$. The charging rate of gas streams and benzyl alcohol (BA) were controlled by a mass flow instrument and syringe pump, respectively. For the control of $\mathrm{O}_{2}$ partial pressure, $\mathrm{N}_{2}$ was used as balance gas and total flow rate was kept at $30 \mathrm{~mL} \mathrm{~min}^{-1}$, of which the $\mathrm{O}_{2}$ flow rate (o to 30 $\left.\mathrm{mL} \min ^{-1}\right)$ was adjusted to certain ratios with benzyl alcohol $\left(1.8 \mathrm{~mL} \mathrm{~min}^{-1}\right)$. In contrast, to determine the reaction rate of benzyl alcohol, oxygen flow rate was fixed at 30 $\mathrm{mL} \mathrm{min}^{-1}$ while the charging rate of benzyl alcohol was 


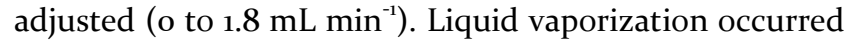
on the reactor wall prior to the catalytic bed. The liquid products and unreacted benzyl alcohol were periodically (every hour) collected during the reaction and analyzed quantitatively by gas chromatography. The selectivity was calculated as mole of produced benzaldehyde per mole of reacted benzyl alcohol and the carbon balance was > 99\% in the case of selectivity near $99 \%$.

\subsection{TPD measurement}

The adsorption and desorption of benzyl alcohol was performed in a fixed bed vertical glass reactor fitted with a glass frit carrying the catalyst ( $1 \mathrm{~g}$ for $0.5 \mathrm{wt} \% \mathrm{Au} / \mathrm{SiO}_{2}$ ). Nitrogen was used as carrier gas and was controlled by a mass flow instrument. To remove the surface hydroxyl groups and the adsorbed oxygen, the catalyst was swept by nitrogen at $250{ }^{\circ} \mathrm{C}$ at a speed of $40 \mathrm{~mL} \mathrm{~min}^{-1}$ for $1 \mathrm{~h}$. After pretreatment, the samples were cooled in the carrier gas to $210{ }^{\circ} \mathrm{C}$. Subsequently, benzyl alcohol was supplied through a syringe pump at a speed of $0.6 \mathrm{~mL} \mathrm{~h}^{-1}$. The adsorption of benzyl alcohol was performed for $1 \mathrm{~h}$ at different speeds $\left(40 \mathrm{~mL} \mathrm{~h}^{-1}, 80 \mathrm{~mL} \mathrm{~h}^{-1}\right.$ and $120 \mathrm{~mL} \mathrm{~h}^{-1}$ ). Then, the nitrogen continued to purge for $1 \mathrm{~h}$ without the flowing of benzyl alcohol to remove the weakly adsorbed species. After this step, the temperature program desorption was carried out from $210{ }^{\circ} \mathrm{C}$ to $420{ }^{\circ} \mathrm{C}$ with a heating rate of $5{ }^{\circ} \mathrm{C} \mathrm{min}{ }^{-1}$. The outlet of the reactor was sealed by cold trap filled with ethanol solution to collect the desorbed molecules. The collected solution was accumulated and detected by GC-FID every five minutes. Toluene was used as the internal standard for quantitative analysis of the desorbed molecules.

\subsection{DFT calculations}

Density functional theory (DFT) calculations were carried out using the Vienna Ab-initio Simulation Package $(\text { VASP })^{21}$. The spin-polarized projector augmented wave (PAW) method ${ }^{22}$ and the Perdew-Burke-Ernzerhof $(\mathrm{PBE})^{23}$ electron exchange-correlation functional of the generalized gradient approximation (GGA) ${ }^{24}$ were applied in our calculations. The kinetic energy cut-off for the wave function expanded in the plane-wave basis was set as $400 \mathrm{eV}$. To optimize the structures, the calculation was performed until the maximum force upon each relaxed atom was less than $0.05 \mathrm{eV} \AA^{-1}$. The vacuum height was set as $15 \AA$ to eliminate the interaction between neighboring slabs. The spin-polarized calculations were carried out with the DFT (PBE) - D3 (BJ) scheme ${ }^{25,26}$ as implemented in VASP. Default values of the dispersion coefficient $\left(C_{6}\right)$ and the vdW radii $\left(R_{o}\right)$ parameters given by Grimme $e^{25,26}$ were employed. The optimized bulk lattice constant for Au was determined to be $4.116 \AA$, in good agreement with the experimental value of $4.078 \AA^{27}$.

The adsorption energy $\left(E_{a d s}\right)$ was calculated as follows:

$$
E_{\text {ads }}=-\left(E_{\text {total }}-E_{\text {substrate }}-E_{\text {gas-phase adsorbate }}\right)
$$

where $E_{\text {total }}$ is the calculated total energy of the adsorption system, $E_{\text {substrate }}$ is the energy of the clean substrate and $\mathrm{E}_{\text {gas-phase adsorbate }}$ is the energy of the gas-phase molecule.

In order to study the adsorption of different alcohols on gold surfaces, we used the following models: a $3 \times 3$ surface cell was used to construct a three-layer $\mathrm{Au}(100)$ slab, a $5 \times 4$ surface cell was used to construct a six-layer $\mathrm{Au}(111)$ slab and a $2 \times 4$ surface cell was used to construct a tenlayer $\mathrm{Au}(211)$ slab. The top two layers of the $\mathrm{Au}(100)$ slab, the top three layers of the $\mathrm{Au}(111)$ slab, and the top five layers of the $\mathrm{Au}(211)$ slab were allowed to relax. The Brillouin-zone integration was performed along with a $2 \times 2 \times 1$ Monkhorst-Pack grid for the different surface slabs.

\section{RESULTS AND DISCUSSION}

3.1 Solvent-driven MTP to SC reversible transformation. AuNPs synthesized by a $\mathrm{NaBH}_{4}$ reduction meth$\mathrm{od}^{18}$ in the presence of dodecanethiol show uniform size distribution $(3.3 \pm 0.5 \mathrm{~nm})$. The high-resolution transmission electron microscopy (HRTEM) image of a representative particle shows five-fold symmetry (Figure 1a), along with apparent stacking faults, indicating that the particles are MTPs. Besides, the spots (Figure $1 \mathrm{~b}$ ) in the Fast Fourier Transform (FFT) pattern also follow an arrangement similar to the reported fivefold symmetry for MTPs $^{28}$. Based on TEM images obtained at three different tilting angles (Figure $\mathrm{S} 1$ ), an icosahedra structure is proposed for AuNPs as demonstrated by the atomic structure model in Figure 1c. We further measured 100 particles in this sample with HRTEM and carefully counted the frequency of MTP. The concentration of MTP is as high as 94\% (Figure S2), suggesting that MTP is the dominant product synthesized by this method.

The as-synthesized AuNPs were loaded onto silica support (denoted as $\mathrm{Au} / \mathrm{SiO}_{2}$ ) by a colloid deposition $\operatorname{method}^{20}$, followed by a calcination at $350{ }^{\circ} \mathrm{C}$ to remove surface capping agents. After calcination, the particle size increases from $3.3 \pm 0.5 \mathrm{~nm}$ to $5.2 \pm 0.8 \mathrm{~nm}$ due to the sintering problem. Interestingly, the supported AuNPs are still MTP dominant (86\%, Figure S3), implying that the loading process has limited influence on the MTP concentration.

It is important to note that post-synthesis modifications of $\mathrm{Au} / \mathrm{SiO}_{2}$ with solvents could dramatically alter the microstructures of AuNPs. The solvent treatment was carried out by washing $\mathrm{Au} / \mathrm{SiO}_{2}$ in different solvents for 3 times, followed by a $5 \mathrm{~h}$ calcination at $350{ }^{\circ} \mathrm{C}$. XPS data (Figure $\mathrm{S}_{4}$ ) show the absence of sulfur on the surface of AuNPs after the thermal treatment at $350{ }^{\circ} \mathrm{C}$, indicating the complete removal of thiols after calcination. This result is well consistent with Khlobystov's report ${ }^{29}$, which shows that thiols capping on the gold begin to vaporize below $300{ }^{\circ} \mathrm{C}$ and can be completely removed at nearly $400 \quad{ }^{\circ} \mathrm{C}$. TEM 


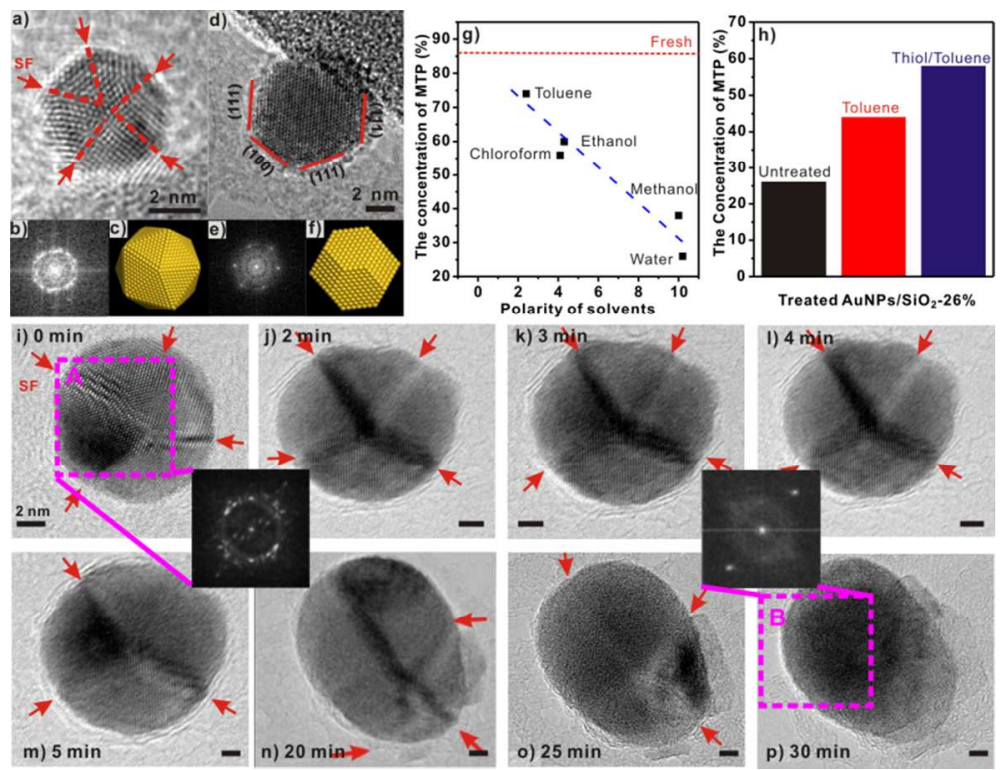

Figure 1. Characterization of solvent-driven MTP-to-SC reversible transformation. (a) HRTEM image, (b) FFT pattern and (c) schematic model of a representative particle in $\mathrm{Au} / \mathrm{SiO}_{2}-86 \%$; (d) HRTEM image, (e) FFT pattern and (f) schematic model of a representative particle in $\mathrm{Au} / \mathrm{SiO}_{2}-26 \%$; $(\mathrm{g})$ The MTP concentration (\%) as a function of polarity of solvents using for postsynthesis modifications; (h) The MTP concentration (\%) of $\mathrm{Au} / \mathrm{SiO}_{2}-26 \%$ after post-synthesis modifications by different nonpolar solvents. (i-p) HRTEM images of gold NPs grown in situ at $350^{\circ} \mathrm{C}$ after water treatment. All scale bars in Figures ii-p are $2 \mathrm{~nm}$. (i, A) Fresh gold NP and its FFT pattern; ( $j \sim m$ ) water-adsorbed AuNPs heated at $350{ }^{\circ} \mathrm{C}$ for first few minutes; $(\mathrm{n} \sim \mathrm{o})$ wateradsorbed AuNPs with prolonged time of heating at $350^{\circ} \mathrm{C}$, and (p) single crystal domain in region $\mathrm{B}$.

and XRD analysis suggested that no visible particle aggregation occurred during the post-synthesis processes (Figures $\mathrm{S}_{5}$ and S6). Figure id shows the HRTEM image of a representative particle of $\mathrm{Au} / \mathrm{SiO}_{2}$ after water treatment. Unlike the spherical morphology of untreated AuNPs, the water-treated AuNPs become faceted as labeled in Figure 1d. Meanwhile, the exposed $\{111\}$ and $\{100\}$ facets labeled in the HRTEM image as well as the FFT pattern unambiguously confirm that the particle has become single-crystal with a truncated octahedral morphology (Figures ie and if). Importantly, statistical data revealed that only $26 \%$ of AuNPs in water-treated $\mathrm{Au} / \mathrm{SiO}_{2}$ were MTP (Figure $\mathrm{S}_{7}$ ), suggesting that the water treatment caused an obvious MTP-to-SC transformation. The sharply decreased MTP concentration (from $86 \%$ to $26 \%$ ), which also means less TBs and SFs, were found to cause different catalytic performance as will be discussed later. For the convenience of writing, all the silica supported AuNPs were denoted as $\mathrm{Au} / \mathrm{SiO}_{2}-\mathrm{X}$, where $\mathrm{X}$ is the concentration of MTP.

To further understand the water-driven structural evolution of gold icosahedra, in situ HRTEM was employed to monitor the heating process of water-adsorbed AuNPs at $350^{\circ} \mathrm{C}$. Control experiments on untreated AuNPs show no noticeable structural change, which confirm the good thermal stability of small sized $\mathrm{MTP}^{30,31}$ and excludes the electron irradiation effect (Figures S8 and S9). AuNPs treated by polar solvents without thermal annealing have similar structures with those of untreated samples, indicating that the structural evolution occurs during the thermal annealing process. The interaction between solvent molecules and the surface of Au NPs, together with the desorption of solvents during thermal annealing might greatly facilitate the MTP-to-SC transformation.
Figures ii-p show a time series of the restructuring process of as-synthesized gold NPs with a size of $\sim 10 \mathrm{~nm}$ after adsorbing water molecules. The fresh gold NP was multiply twinned along with a high probability of SFs as indicated by the FFT from region A. The contrasts for TBs were marked by red arrows (Figure ii). When heated at $350^{\circ} \mathrm{C}$, only a slight morphology change was observed in the first few minutes, which included the appearance of concave and convex surface features (Figures $1 j \sim \mathrm{m}$ ). After prolonged heating, the NP was elongated, accompanied by the movement of TBs (Figure in). Further heating led to the gradual disappearance of TBs and SFs (Figures 10 and 1p), which was evidenced by the FFT of region B. At the same time, the NP crystallized from one single-crystal segment of the MTP and continued to grow to a larger crystal with faceted edges protruding from the NP surface (Figure 1p). The gold NPs finally experienced a complete MTP-to-SC restructuring similarly as observed in Figure $1 d$. We note that the mechanism of MTP-to-SC transformation merit detailed study and will be presented elsewhere.

Interestingly, $\mathrm{Au} / \mathrm{SiO}_{2}$ treated by different solvents (e.g. toluene, chloroform, ethanol, methanol and water) show different MTP concentrations (Figures $\mathrm{S}_{7}$ and Sio). Figure $1 \mathrm{~g}$ plots the concentration of MTPs as the function of the polarity of the treatment solvents ${ }^{32}$. The quasi-linear plot suggests that the MTP-to-SC transformation is correlated to the polarity of the solvent molecules. The higher of the polarity, the lower of the MTP concentration. It is likely that polar solvents have stronger interaction with AuNPs which drive more significant restructuring as compared to nonpolar solvents ${ }^{33}$. Similar structural evolution has been reported in other systems. Banfield and her 
coworkers described that water can drive $\mathrm{ZnS}$ nanoparticle undergo structural change with significantly reduced surface and interior distortion owing to its strong interaction with the $\mathrm{ZnS}$ surface ${ }^{34}$. Li et al. demonstrated that solvent exchange of ethanol by hexane leads to quick selective desorption of the thiolate layers from $\mathrm{Au}$ nanocluster surface which subsequently results in an icosahedral to cuboctahedral structure transformation ${ }^{35}$.

From the viewpoint of surface science, it is also of great interest to know the reversibility of this transformation. To this end, we employed SC dominant gold sample $\left(\mathrm{Au} / \mathrm{SiO}_{2}-26 \%\right)$ as a source material and treated it with nonpolar solvents. It turns out that toluene treatment could increase the MTP concentration from $26 \%$ to $44 \%$ (Figure $\mathrm{ih}$ ). Moreover, the MTP concentration could be doubled to $58 \%$ with a treatment with thiol/toluene solution (Figure S11). It is likely that the treatment of thiol/toluene and prolonged annealing at $350{ }^{\circ} \mathrm{C}$ will facilitate the SC-to-MTP transformation. According to a previous study carried out by Zhu et al., the thiol ligands tend to bond strongly with the densest $\mathrm{Au}\{111\}$ facets to minimize the surface energy ${ }^{36}$, which acts as a thermodynamic driving force here for the SC-to-MTP transformation due to the maximization of $\{111\}$ facets in the Au MTPs. These results not only confirm the good reversibility of the MTP-to-SC transformation, but also demonstrate a practical approach to enrich the MTP concentration and thus the TBs and SFs of AuNPs. MTPs are rich in twin boundaries exposed with high-index \{211\}-like facets, along with a internal lattice strain ${ }^{11,37}$. Such structures will directly influence the bonding strength for adsorbates, and may result in a major modification of their catalytic properties.

3.2 Gas-phase selective oxidation of alcohols with molecular oxygen. Gas-phase selective alcohol oxidation is widely recognized as one of the most fundamental transformations in both laboratory and industrial synthetic chemistry since the partial oxidation products (aldehyde/ketone) serve as most important molecules in cosmetics, perfumery, food and pharmaceutical industries $^{38}$. During recent years, an increasing effort has been made to apply "green" methods and to replace traditional stoichiometric oxidants by molecular oxygen. ${ }^{39}$ The most challenging part of the gas-phase oxidation with molecular oxygen remains in its limited activity and selectivity as compared to the liquid-phase processes ${ }^{40-42}$. Supported AuNPs catalysts have been explored as promising candidates for this reaction ${ }^{20}$, but the origin of their excellent activity is still unclear. There is limited information about active sites for $\mathrm{BA}$ and $\mathrm{O}_{2}$ chemsorption, let alone the rate-determining step of the reaction. In addition, a comprehensive understanding on the structure-activity relationship is still unavailable.

Previous studies revealed that the activity and selectivity of gold NPs not only depend on the particle size and the exposed crystallographic facets, but also correlate to additional structural features, such as the degree of particle rounding or the multiple twinning properties ${ }^{13,14,43,44}$. Luckily, the post-synthesis method has negligible influ- ence on the particle size and valence state of the supported AuNPs as confirmed by TEM, XRD and XPS analysis (Figures $\mathrm{S}_{5}$, S6 and $\mathrm{S}_{12}$ ). Besides, control experiments also confirmed the complete removal of surface ligand (Figure $\mathrm{S}_{4}$ and Table $\mathrm{S}_{1}$ ). Therefore, these AuNPs with variable MTP concentrations could serve as an excellent model to investigate the twin effect on their catalytic properties.
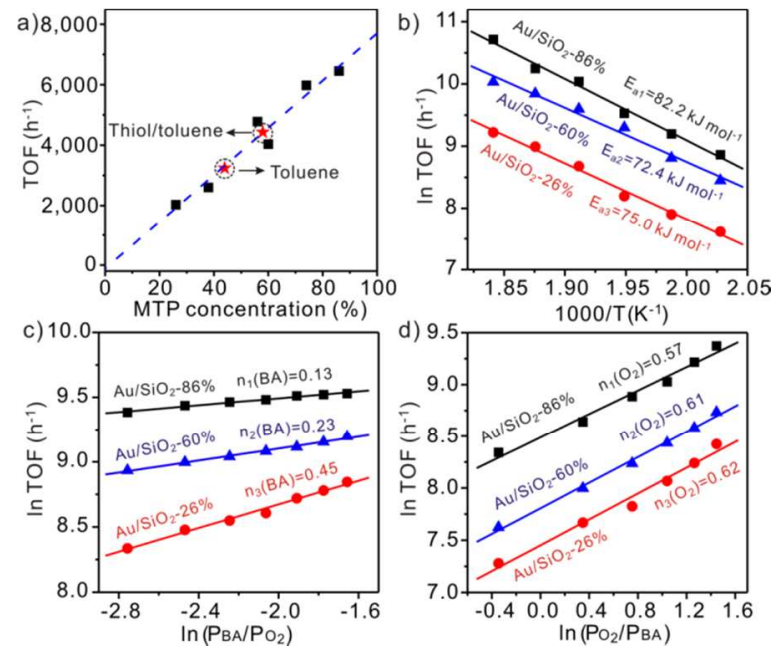

Figure 2. Catalytic tests and kinetic studies of $\mathrm{AuNPs} / \mathrm{SiO}_{2}$ with different MTP concentrations. (a) TOF $\left(220^{\circ} \mathrm{C}\right)$ value as a function of the MTP concentration for catalytic selective oxidation of BA. Catalytic results of toluene and thiol/toluene treated $\mathrm{Au} / \mathrm{SiO}_{2}-26 \%$ are indicated by red stars. Reaction conditions: catalyst $=20 \mathrm{mg}$, benzyl alcohol $=1.8$ $\mathrm{mL} \min ^{-1}, \mathrm{O}_{2}=30 \mathrm{~mL} \mathrm{~min}^{-1}, \mathrm{~T}=220{ }^{\circ} \mathrm{C}$. (b) The Arrhenius plots of $\mathrm{Au} / \mathrm{SiO}_{2}-86 \%, \mathrm{Au} / \mathrm{SiO}_{2}-60 \%$ and $\mathrm{Au} / \mathrm{SiO}_{2}-26 \%$; (c) The influence of oxygen and (d) BA partial pressure on catalytic selective oxidation of $\mathrm{BA}$ over the $0.5 \mathrm{wt} \% \mathrm{Au} / \mathrm{SiO}_{2}-$ $86 \%, \mathrm{Au} / \mathrm{SiO}_{2}-60 \%$ and $\mathrm{Au} / \mathrm{SiO}_{2}-26 \%$. In all cases, the selectivity is $>98 \%$.

Figure 2a plots the turnover frequency (TOF) values as the function of the MTP concentrations. Here, TOF values are defined as benzyl alcohol reacted per hour per surface $\mathrm{Au}$ atom. By taking the gold particle as a sphere, the ratio between the surface gold atoms and the total gold atoms (i.e. dispersion, D) was roughly calculated by $\mathrm{D}=1.3 / \mathrm{d}_{\mathrm{Au}}(\mathrm{nm})$, where $\mathrm{d}_{\mathrm{Au}}$ is the average particle size determined from XRD patterns by Scherrer equation. ${ }^{45}$ Generally, the TOF values decrease with the decline of the MTP concentrations. The supported AuNPs with high MTP concentration show excellent catalytic activity towards gas-phase benzyl alcohol oxidation even at relatively low temperature $\left(220{ }^{\circ} \mathrm{C}\right)$. The highest turnover frequency $\left(\mathrm{Au} / \mathrm{SiO}_{2}-84 \%\right)$ is up to ca. $6500 \mathrm{~h}^{-1}\left(220{ }^{\circ} \mathrm{C}\right)$. Though this value cannot compare to the state-of-art one $^{41,42}$ in liquid-phase oxidation of benzyl alcohol, it actually surpasses the TOF for most of supported gold catalysts in gas-phase oxidation of benzyl alcohol ${ }^{46}$. AuNPs with the lowest MTP concentration $\left(\mathrm{Au} / \mathrm{SiO}_{2}-26 \%\right)$ give the lowest TOF value $\left(2030 \mathrm{~h}^{-1}\right)$, which is only one third of that of $\mathrm{Au} / \mathrm{SiO}_{2}-86 \%$. Nevertheless, the TOF is still higher than that reported by Rossi et $\mathrm{al}^{38}$. Notably, there is a quasi-linear relationship between TOFs and MTP concentrations, demonstrating that MTPs play a 

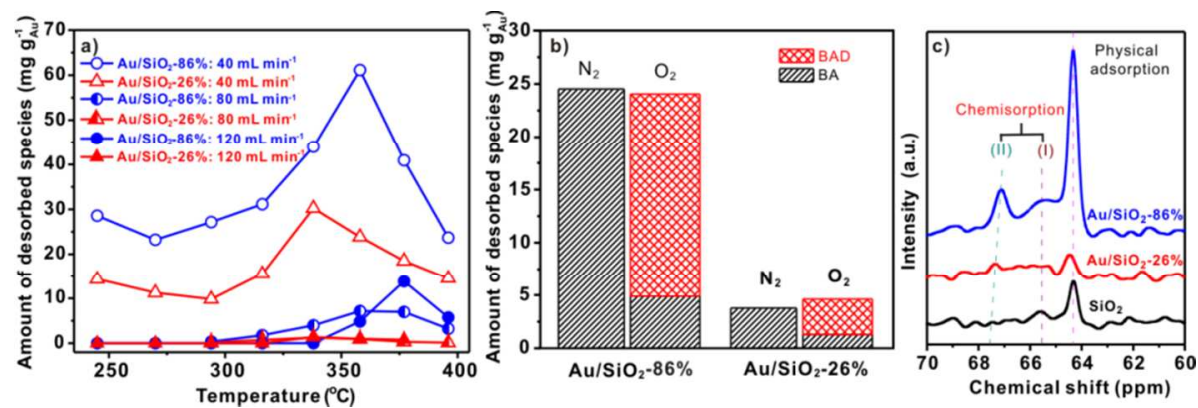

Figure 3. Quantitative analysis of $\mathrm{BA}$ adsorption on $\mathrm{Au} / \mathrm{SiO}_{2}-86 \%$ and $\mathrm{Au} / \mathrm{SiO}_{2}-26 \%$. (a) TPD of $\mathrm{BA}$ at a $\mathrm{N}_{2}$ flowing speed of 40 , 80 and $120 \mathrm{~mL} \mathrm{~min}^{-1}$ in the temperature range of $240-400{ }^{\circ} \mathrm{C}$; (b) The total amount of desorbed BA and BAD at a speed of 120 $\mathrm{mL} \min ^{-1}$ from 240 to $400{ }^{\circ} \mathrm{C}$ in the atmosphere of $\mathrm{N}_{2}$ and $\mathrm{O}_{2} ;(\mathrm{c}){ }^{13} \mathrm{C}$ solid-state NMR spectra of adsorbed BA molecules on different catalysts acquired under quantitative direct polarization.

significant role in selective oxidation of benzyl alcohol. As has been extensively discussed above, MTPs are rich in SFs and TBs which are accompanied by high-index $\{211\}$ facets. Such sites usually exhibit lower coordination number and thus high activities. It is reasonable to hypothesize that the presence of TBs and SFs as defects in nanosized gold icosahedra mainly accounts for their low temperature activity towards the gas phase alcohol selective oxidation. Passivating these sites by solvent-induced restructuring could dramatically deactivate the gold catalyst.

Besides, we also tested the catalytic performances of toluene and thiol/toluene treated $\mathrm{Au} / \mathrm{SiO}_{2}-26 \%$. In line with the SC-to-MTP transformation, those samples exhibit superior catalytic performance than $\mathrm{Au} / \mathrm{SiO}_{2}-26 \%$. More interestingly, they also fall into the quasi-linear plot of TOFs and MTP concentrations as indicated by red stars in Figure 2a. The TOF values for pure MTP and SC AuNPs can be calculated according to the linear correlation. As can be seen from Figure $2 \mathrm{a}$, the pure MTP is highly active $\left(\mathrm{TOF}>7000 \mathrm{~h}^{-1}\right)$ while pure SC is almost inert. These results then further emphasize the importance of TBs and SFs. It also implies that only MTP AuNPs are responsible to the high activity for low-temperature gas-phase BA oxidation.

3.3 Comparison studies of the reaction kinetic on $\mathrm{Au} / \mathrm{SiO}_{2}-86 \%, \mathrm{Au} / \mathrm{SiO}_{2}-60 \%$ and $\mathrm{Au} / \mathrm{SiO}_{2}-26 \%$. To monitor reaction profiles and analyze reaction kinetics is very useful for illuminating mechanistic details. Figure $2 \mathrm{~b}$ shows the Arrhenius plots of $\mathrm{Au} / \mathrm{SiO}_{2}-86 \%, \mathrm{Au} / \mathrm{SiO}_{2}-60 \%$ and $\mathrm{Au} / \mathrm{SiO}_{2}-26 \%$. The apparent activation energies of $\mathrm{BA}$ oxidation over $\mathrm{Au} / \mathrm{SiO}_{2}-86 \%\left(82.2 \mathrm{~kJ} \mathrm{~mol}{ }^{-1}\right), \mathrm{Au} / \mathrm{SiO}_{2}-$ $60 \%\left(72.4 \mathrm{~kJ} \mathrm{~mol}^{-1}\right)$ and $\mathrm{Au} / \mathrm{SiO}_{2}-26 \%\left(75.0 \mathrm{~kJ} \mathrm{~mol}^{-1}\right)$ are almost the same, indicating identical active sites for BA oxidation in these cases. This result leads us to the conclusion that the difference in TOFs among $\mathrm{Au} / \mathrm{SiO}_{2}-$ $86 \%, \mathrm{Au} / \mathrm{SiO}_{2}-60 \%$ and $\mathrm{Au} / \mathrm{SiO}_{2}-26 \%$ is mainly determined by the number of active sites. Interestingly, if TBs and SFs (defect) sites are the active sites as one may expect, the phenomenon can be well understood since the number of defect sites decreases proportionally to the MTP concentrations.

Additionally, we carried out partial pressure experiments to determine the apparent reaction order of each reactant. As shown in Figure 2c, there is a small change of the reaction order of $\mathrm{O}_{2}$ molecules on $\mathrm{Au} / \mathrm{SiO}_{2}-$ $86 \%, \mathrm{Au} / \mathrm{SiO}_{2}-60 \%$ and $\mathrm{Au} / \mathrm{SiO}_{2}-26 \%$ (o.57, o.61 and 0.62 ), suggesting that $\mathrm{O}_{2}$ activation is not significantly influenced by the MTP concentration. In contrast, the reaction order of BA molecules closely depends on the MTP concentration (Figure 2d). The reaction order of BA on $\mathrm{Au} / \mathrm{SiO}_{2}-86 \%$ is as low as 0.13 , which is only one third of $\mathrm{Au} / \mathrm{SiO}_{2}-26 \%$ (o.45). According to the classic theory, lower reaction order indicates stronger adsorption on the surface of the catalyst ${ }^{35}$. Therefore, the MTP-to-SC transformation eventually decreases the $\mathrm{BA}$ adsorption strength. In other words, $\mathrm{Au} / \mathrm{SiO}_{2}-86 \%$ could adsorb more BA molecules than $\mathrm{Au} / \mathrm{SiO}_{2}-26 \%$ due to its more abundant defect sites.

The BA chemisorption was then determined by TPD measurement and solid-state NMR spectrum analysis. The convenience in controlling the flowing speed and atmosphere facilitates the separation of physical adsorption from chemisorption and thus can help determine the reaction mechanism. As shown in Figure $3 a$, at lower space velocity $\left(40 \mathrm{~mL} \mathrm{~min}^{-1}\right.$ ) in the $\mathrm{N}_{2}$ atmosphere, there was a large amount of desorbed BA molecules on both $\mathrm{Au} / \mathrm{SiO}_{2}-86 \%$ and $\mathrm{Au} / \mathrm{SiO}_{2}-26 \%$ over the full temperature range, which mainly comprised of the physical adsorption. In contrast, at higher flowing speeds (8o and $120 \mathrm{~mL} \mathrm{~min}$ $\left.{ }^{1}\right)$, considerable desorption took place only at temperatures higher than $325^{\circ} \mathrm{C}$, likely due to the strong interaction between chemisorbed BA and AuNPs. Notably, at both flowing speeds, the amount of desorbed BA molecules on $\mathrm{Au} / \mathrm{SiO}_{2}-86 \%$ is larger than that on $\mathrm{Au} / \mathrm{SiO}_{2}-26 \%$. Specifically, the concentration of chemisorbed BA on $\mathrm{Au} / \mathrm{SiO}_{2}-86 \%$ is $24.2 \mathrm{mg} \mathrm{g}_{\mathrm{Au}}{ }^{-1}$, which is about 4-5 times as much as that on $\mathrm{Au} / \mathrm{SiO}_{2}-26 \%$ (3.2 $\mathrm{mg} \mathrm{g}_{\mathrm{Au}}{ }^{-1}$ ), coinciding with the MTP concentrations. Based on the amount of chemisorbed BA molecules and the loading of AuNPs, the ratio of $\mathrm{BA}$ molecules to surface gold atoms $\left(\mathrm{BA} / \mathrm{Au}_{\mathrm{surf}}\right)$ on $\mathrm{Au} / \mathrm{SiO}_{2}-86 \%$ and $\mathrm{Au} / \mathrm{SiO}_{2}-26 \%$ is identified to be ca. 0.16 and ca. 0.04 , respectively. This result, in line with the kinetic study, reveals different BA-chemisorption capacities of MTP and SC. More interestingly, after we switched the carrying gas from $\mathrm{N}_{2}$ to $\mathrm{O}_{2}$, most of the adsorbed BA molecules $(78 \%)$ converted into benzaldehyde (Figure $3 \mathrm{~b})$. It unambiguously confirms their chemisorption nature and that these chemisorption sites also act as active sites for 
Table 1. Aerobic oxidation of various alcohols.

\begin{tabular}{ccccccc}
\hline \multirow{2}{*}{ Reactants } & \multicolumn{3}{c}{$\mathbf{H}_{\text {chemisorption }}(\mathbf{e V})^{\mathbf{a}}$} & \multicolumn{3}{c}{ TOF $\left(\mathbf{h}^{-1}\right)$ at 220 ${ }^{\circ} \mathbf{C}$} \\
\cline { 2 - 7 } & $\mathrm{Au}(100)$ & $\mathrm{Au}(111)$ & $\mathrm{Au}(211)$ & $\mathrm{Au} / \mathrm{SiO}_{2}-26 \%$ & $\mathrm{Au} / \mathrm{SiO}_{2}-58 \%$ & Enhancement \\
\hline BA & 1.33 & 1.23 & 1.52 & 1925 & 4841 & 2.51 \\
n-hexanol & 1.15 & 1.03 & 1.14 & 1132 & 3700 & 3.26 \\
n-heptanol & 1.27 & 1.32 & 1.34 & 1156 & 1504 & 1.30 \\
n-octanol & 1.44 & 1.48 & 1.55 & 488 & 1184 & 2.64 \\
\hline
\end{tabular}

Reaction conditions: $\mathrm{O}_{2}$ flowed at a rate of $30 \mathrm{~mL} \mathrm{~min}^{-1}$, liquid alcohols were supplied by a syringe pump at a rate of $1.8 \mathrm{~mL} \mathrm{~h}^{-1}$ and catalysts masses were $20 \mathrm{mg}$. In all cases, selectivities are $>99 \%$. ${ }^{\mathrm{a}}$ The chemisorption energies of alcohols on $\mathrm{Au}(100), \mathrm{Au}(111)$ and $\mathrm{Au}(211)$ were predicted by DFT calculations.

BA selective oxidaton. We can thus correlate the catalytic performance to the ability of chemisorption which is determined by the structure (e.g. MTP, SC) of the catalyst. In specific, MTP has a strong chemisorption capability for benzyl alcohol and then acts as the active phase. SC cannot chemisorb benzyl alcohol and is thus inactive for this reaction, cosistent with the extrapolation shown in Figure 2a. Fundementally, the post-treatment approach adjusts the activity of $\mathrm{Au} / \mathrm{SiO}_{2}$ by tuning the number of active sites (i.e. MTP concentration).

More accurate quantitative characterization of the chemisorbed BA molecules on catalysts was conducted by solid-state NMR. BA-adsorbed catalysts were pretreated by a high flowing speed of $\mathrm{N}_{2}$ for $1 \mathrm{~h}$ to remove most physical adsorbed BA molecules. The methyl carbon in BA molecule was $50 \%$ enriched by ${ }^{13} \mathrm{C}$ isotope for clear signal. Adamantane was used as an internal calibration material and pure $\mathrm{SiO}_{2}$ was employed as the control. Solid-state NMR spectra of $\mathrm{BA}$-adsorbed $\mathrm{Au} / \mathrm{SiO}_{2}$ show three distinct signals (Figure $3 \mathrm{C}$ ). The one appearing at $\sim 64.5 \mathrm{ppm}$ belongs to the physical adsorbed BA molecule, and it was further confirmed by the control experiment on pure $\mathrm{SiO}_{2}$. Two lower peaks (65.5 ppm, 67.3 ppm) are assigned to the chemisorbed BA molecules that have stronger interaction with $\mathrm{Au} / \mathrm{SiO}_{2}$. Notably, the ratio of chemisorbed molecules to surface gold atoms on $\mathrm{Au} / \mathrm{SiO}_{2}-86 \%$ and $\mathrm{Au} / \mathrm{SiO}_{2}-$ $26 \%$ is ca. 0.15 and ca. 0.04, respectively, in good agreement with the results obtained by TPD measurement (0.16 and 0.04).

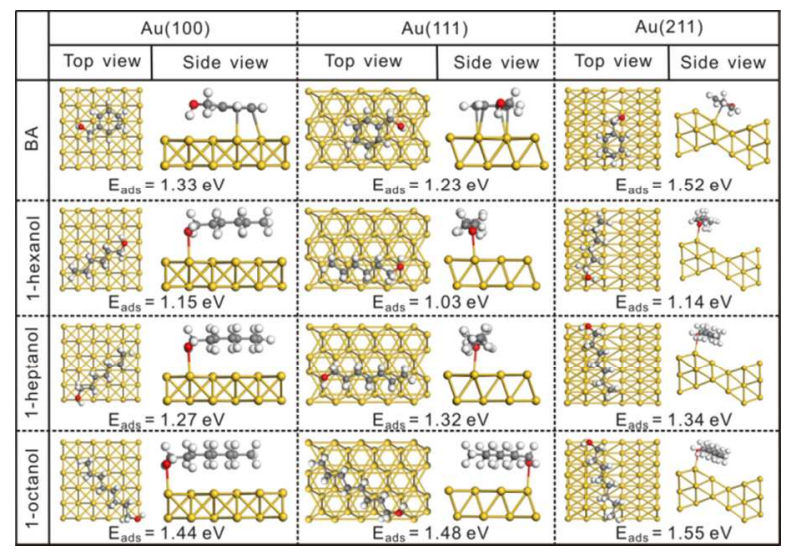

Figure 4. Different binding configurations and corresponding adsorption energies of alcohols on $\mathrm{Au}(100), \mathrm{Au}(111)$ and Au(211). Au (golden), C (grey), O (red), H (white).
In gas-phase catalytic reaction, BA molecules have firstly to be brought to the surface active sites of AuNPs, where they can be chemisorbed in the right form and with minimum energy, to ensure that their adsorbed states are sufficiently reactive. To rationalize the experimental observations, we further performed density functional theory (DFT) calculations to determine the adsorption properties of model gold surfaces. As suggested by Choi and his coworkers, the icosahedron with a gap of 1.54 steradians will cause large elastic lattice strain and result in the appearance of multiple twin boundaries that are frequently accompanied with adjacent stacking faults and nanotwinning domains. Such twin domains could expose $\{211\}$ facets while other active sites might expose $\{111\}$ and $\{100\}$ facets ${ }^{11}$. The optimized configurations and adsorption energies are summarized in Figure 4. The adsorption energy of benzyl alcohol on $\mathrm{Au}(211)$ is higher than those on $\mathrm{Au}(100)$ and $\mathrm{Au}(111)$ by 0.19 and $0.29 \mathrm{eV}$, respectively. Consequently, the MTP-rich catalyst (more $\mathrm{Au}(211)$ sites) could adsorb more benzyl alcohol molecules than the SC-rich catalyst. Besides, as the number of adsorbed BA molecules increases, the calculated adsorption energies have almost no change (Figure $\mathrm{S}_{13}$ ), showing no obvious coverage effect of benzyl alcohol on such surface. In addition, when two molecules of benzyl alcohol were adsorbed on $\mathrm{Au}(211)$, each molecule takes 9 10 Au atoms. The ratio of chemisorbed molecules to surface gold atoms is ca. 0.10 , close to the value determined by NMR and TPD measurements.

3.4 Optimize gold catalysts for alcohol oxidation by tuning their microstructures. Understanding the factors that influence the growth and final shape of noble metal nanostructures is important for tuning their properties. As has been extensively discussed above, the unique interaction between thiol/toluene and AuNPs could drive the restructuring of SC-to-MTP to increase the twin defects and subsequently enhance their catalytic performance for selective oxidation of BA. On the other hand, we also evaluated the adsorption properties of 1hexanol, 1-heptanol and 1-octanol on the Au surfaces by DFT calculations. As shown in Figure 4, the adsorption energies on $\mathrm{Au}(211)$ are always higher than those on $\mathrm{Au}(111)$ and $\mathrm{Au}(100)$ regardless of the type of alcohols. It then can be expected that MTP-dominant Au catalysts might also exhibit better catalytic performance for the oxidation of other alcohols. In this work, we also conducted the catalytic oxidation of 1-hexanol, 1-heptanol and 1-octanol 
Table 2. TOF values of different gold catalysts before and after thiol/toluene treatment.

\begin{tabular}{cccccc}
\hline \multirow{2}{*}{ Catalysts } & \multicolumn{2}{c}{ MTP concentration } & \multicolumn{3}{c}{ TOF $\left(\mathbf{h}^{-1}\right)$ at 220 ${ }^{\circ} \mathbf{C}$} \\
\cline { 2 - 6 } & before & after & before & after & enhancement \\
\hline $\mathbf{A u} / \mathbf{S i O}_{2}-\mathbf{2 6} \%$ & $26 \%$ & $58 \%$ & 1925 & 4841 & 2.51 \\
$\mathrm{Au} / \mathbf{S i O}_{2}-\mathbf{D P}^{48}$ & $18 \%$ & $52 \%$ & 2189 & 4146 & 1.89 \\
$\mathrm{Au} / \mathbf{S i O}_{2}-\mathbf{I m}^{47}$ & - & - & 850 & 1933 & 2.27 \\
$\mathrm{Au} / \mathbf{S i O}_{2}-\mathbf{C P}^{49}$ & - & - & 1044 & 1956 & 1.87 \\
\hline
\end{tabular}

Reaction conditions: $\mathrm{O}_{2}$ flowed at a rate of $30 \mathrm{~mL} \mathrm{~min}^{-1}$, benzyl alcohol was supplied by a syringe pump at a rate of $1.8 \mathrm{~mL} \mathrm{~h}^{-1}$ and catalysts masses were $20 \mathrm{mg}$. In all cases, selectivities to benzaldehyde are $>99 \%$.

on both $\mathrm{Au} / \mathrm{SiO}_{2}-26 \%$ and $\mathrm{Au} / \mathrm{SiO}_{2}-58 \%$ catalysts. The $\mathrm{Au} / \mathrm{SiO}_{2}-58 \%$ is obtained by post-treating $\mathrm{Au} / \mathrm{SiO}_{2}-26 \%$ with thiol/toluene. The MTP concentration is determined by HRTEM. Table 1 lists the TOF values of $\mathrm{Au} / \mathrm{SiO}_{2}-26 \%$ and $\mathrm{Au} / \mathrm{SiO}_{2}-58 \%$. An enhancement over 1.3 (typically, >2.5) in TOFs were obtained for all these alcohols (1hexanol, 1-heptanol and 1-octanol), confirming the potential application of this post-synthesis method to optimize their interaction with reactants and corresponding activity.

More importantly, the solvent-driven SC-to-MTP transformation is also valid for supported AuNPs prepared by other methods including impregnation $\left(\mathrm{Au} / \mathrm{SiO}_{2}-\mathrm{Im}\right)^{47}$, deposition precipitation $\left(\mathrm{Au} / \mathrm{SiO}_{2}-\mathrm{DP}\right)^{48}$ and coprecipitation $\left(\mathrm{Au} / \mathrm{SiO}_{2}-\mathrm{CP}\right)^{49,50}$. As indicated in Table 2 , the catalytic activities are roughly enhanced by a factor of $1.87-2.51$ after thiol/toluene treatment, consistent with the typical increased MTP concentration (2.2 times). This result then serves as a proof for the structure-activity correlation, and it also greatly expands the applications of the postsynthesis approach in practical cases.

\section{CONCLUSIONS}

Here we describe a simple post-synthesis approach to reshape the AuNPs with two different microstructures. The binding of polar solvents, especially water, to the MTP-dominant Au catalysts leads to a transformation of MTP to SC, while the binding of thiol/toluene results in a reversible SC-to-MTP transformation. The crossover of the two microstructures allows a facile tuning of their population and reveals the twin effect in catalytic alcohol selective oxidation. A quasi-linear relationship between MTP concentration and catalytic activity implies that twin boundaries exposed with $\{211\}$-like facets are essential for the selective oxidation of alcohols. Experimental evidences as well as DFT calculations confirm that such sites can significantly enhance the chemisorption of alcohol molecules and therefore greatly improve the selective chemical conversion.

\section{ASSOCIATED CONTENT}

Supporting Information. Materials, synthetic details for $\mathrm{Au} / \mathrm{SiO}_{2}-\mathrm{Im}, \mathrm{Au} / \mathrm{SiO}_{2}-\mathrm{DP}$ and $\mathrm{Au} / \mathrm{SiO}_{2}-\mathrm{CP}$, experimental details for solid-state NMR, XRD patterns, XPS data, additional TEM images and DFT calculations. This material is available free of charge via the Internet at http://pubs.acs.org.

\section{AUTHOR INFORMATION}

\section{Corresponding Author}

*jfan@zju.edu.cn

*xueshan199@163.com

*xgong@ecust.edu.cn

\section{Author Contributions}

$\$$ These authors contributed equally.

\section{ACKNOWLEDGMENT}

This work was supported by National Natural Science Foundation of China (21271153, 21421004, 21373181, 21222307,U1402233), Major Research Plan Of National Natural Science Foundation of China (91545113, 91545103), Fok Ying Tung Education Foundation (131015) and the Fundamental Research Funds for the Central Universities (2014XZZXoo3-02).The authors are grateful to the King Abdullah University of Science and Technology (KAUST) in Saudi Arabia for providing the characterization of the in situ HRTEM.

\section{REFERENCES}

(1) Turner, M.; Golovko, V. B.; Vaughan, O. P. H.; Abdulkin, P.; Berenguer-Murcia, A.; Tikhov, M. S.; Johnson, B. F. G.; Lambert, R. M. Nature 2008, 454, 981.

(2) Vaughan, O. Nature Nanotech. 2010, 5, 5.

(3) Hutchings, G. J. Catal. Today 2005, 100, 55.

(4) Fujita, T.; Guan, P.; McKenna, K.; Lang, X.; Hirata, A.; Zhang, L.; Tokunaga, T.; Arai, S.; Yamamoto, Y.; Tanaka, N.; Ishikawa, Y.; Asao, N.; Yamamoto, Y.; Erlebacher, J.; Chen, M. Nature Mater. 2o12, 11, 775 .

(5) Williams, W. D.; Shekhar, M.; Lee, W.-S.; Kispersky, V.; Delgass, W. N.; Ribeiro, F. H.; Kim, S. M.; Stach, E. A.; Miller, J. T.; Allard, L. F. J. Am. Chem. Soc 2010, 132, 14018.

(6) Carrasquillo-Flores, R.; Ro, I.; Kumbhalkar, M. D.; Burt, S.; Carrero, C. A.; Alba-Rubio, A. C.; Miller, J. T.; Hermans, I.; Huber, G. W.; Dumesic, J. A. J. Am. Chem. Soc 2015, 137, 10317.

(7) Shekhar, M.; Wang, J.; Lee, W.-S.; Williams, W. D.; Kim, S. M.; Stach, E. A.; Miller, J. T.; Delgass, W. N.; Ribeiro, F. H. J. Am. Chem. Soc 2012, 134, 4700.

(8) Zhang, Q.; Xie, J.; Yu, Y.; Yang, J.; Lee, J. Y. Small 2010, 6, 523.

(9) Li, Z. Y.; Young, N. P.; Di Vece, M.; Palomba, S.; Palmer, R. E.; Bleloch, A. L.; Curley, B. C.; Johnston, R. L.; Jiang, J.; Yuan, J. Nature 2008, 451, 46.

(10) Wells, D. M.; Rossi, G.; Ferrando, R.; Palmer, R. E. Nanoscale 2015, 7, 6498.

(11) Choi, S.-I.; Herron, J. A.; Scaranto, J.; Huang, H.; Wang, Y.; Xia, X.; Lv, T.; Park, J.; Peng, H.-C.; Mavrikakis, M.; Xia, Y. ChemCatChem 2015, 7, 2077.

(12) Baletto, F.; Ferrando, R. Rev. Mod. Phys. 2005, 77, 371.

(13) He, R.; Wang, Y.-C.; Wang, X.; Wang, Z.; Liu, G.; Zhou, W.; Wen, L.; Li, Q.; Wang, X.; Chen, X.; Zeng, J.; Hou, J. G. Nature Commun. 2014, 5 .

(14) Wang, L.; Zhao, S.; Liu, C.; Li, C.; Li, X.; Li, H.; Wang, Y.; Ma, C.; Li, Z.; Zeng, J. Nano Lett. 2015, 15, 2875. 
(15) Langille, M. R.; Zhang, J.; Personick, M. L.; Li, S.; Mirkin, C. A. Science 2012, 337, 954.

(16) Carbó-Argibay, E.; Rodríguez-González, B. Israel J. Chem. 2016, 56,214 .

(17) Xia, Y.; Xiong, Y.; Lim, B.; Skrabalak, S. E. Angew. Chem. Int. Ed. 2009, 48, 60 .

(18) Zheng, N.; Fan, J.; Stucky, G. D. J. Am. Chem. Soc 20o6, 128, 6550 .

(19) Stöber, W.; Fink, A.; Bohn, E. J. Colloid Interf. Sci. 1968, 26, 62. (20) Ma, G.; Yan, X.; Li, Y.; Xiao, L.; Huang, Z.; Lu, Y.; Fan, J. J. Am. Chem. Soc 2010, 132, 9596.

(21) Kresse, G.; Furthmüller, J. Phys. Rev. B 1996, 54, 11169.

(22) Blöchl, P. E. Phys. Rev. B 1994, 50, 17953.

(23) Perdew, J. P.; Burke, K.; Ernzerhof, M. Phys. Rev. Lett. 1996, 77, 3865 .

(24) Teter, M. P.; Payne, M. C.; Allan, D. C. Phys. Rev. B 1989, 40, 12255 .

(25) Grimme, S.; Antony, J.; Ehrlich, S.; Krieg, H. J. Chem. Phys. 2010, 132, 154104 .

(26) Grimme, S.; Ehrlich, S.; Goerigk, L. J. Comput. Chem. 2011, 32, 1456.

(27) Haynes, W. M.; Lide, D. R.; Bruno, T. J. CRC handbook of chemistry and physics; CRC press, 2011.

(28) Abe, E. Chem. Soc. Rev. 2012, 41, 6787.

(29) La Torre, A.; Giménez-López, M. d. C.; Fay, M. W.; Rance, G. A.; Solomonsz, W. A.; Chamberlain, T. W.; Brown, P. D.; Khlobystov, A. N. ACS Nano 2012, 6, 2000.

(30) Ajayan, P. M.; Marks, L. D. Phase Transitions 1990, 24-26, 229.

(31) Ino, S. J. Phys. Soc. Japan 1969, 27, 941.

(32) Snyder, L. R. J. Chromatogr. A 1974, 92, 223.

(33) Somorjai, G. A.; Van Hove, M. A. Prog. Surf. Sci. 1989, 30, 201.

(34) Zhang, H.; Gilbert, B.; Huang, F.; Banfield, J. F. Nature 2oo3, 424,1025 .
(35) Li, Y.; Cheng, H.; Yao, T.; Sun, Z.; Yan, W.; Jiang, Y.; Xie, Y.; Sun Y.; Huang, Y.; Liu, S.; Zhang, J.; Xie, Y.; Hu, T.; Yang, L.; Wu, Z.; Wei, S. J. Am. Chem. Soc 2012, 134, 17997.

(36) Zhu, Y.; He, J.; Shang, C.; Miao, X.; Huang, J.; Liu, Z.; Chen, H.; Han, Y. J. Am. Chem. Soc 2014, 136, 12746.

(37) Walsh, M. J.; Yoshida, K.; Kuwabara, A.; Pay, M. L.; Gai, P. L.; Boyes, E. D. Nano Lett. 2012, 12, 2027.

(38) Della Pina, C.; Falletta, E.; Rossi, M. J. Catal. 2008, 26o, 384.

(39) Ertl, G.; Knözinger, H.; Schüth, F.; Weitkamp, J. Handbook of heterogeneous catalysis; and ed.; Wiley-VCH: Weinheim, 2008.

(40) Fan, J.; Dai, Y.; Li, Y.; Zheng, N.; Guo, J.; Yan, X.; Stucky, G. D. J. Am. Chem. Soc 2009, 131, 15568.

(41) Enache, D. I.; Edwards, J. K.; Landon, P.; Solsona-Espriu, B.; Carley, A. F.; Herzing, A. A.; Watanabe, M.; Kiely, C. J.; Knight, D. W.; Hutchings, G. J. Science 2006, 311, 362.

(42) Su, F.-Z.; Liu, Y.-M.; Wang, L.-C.; Cao, Y.; He, H.-Y.; Fan, K.-N. Angew. Chem. 2008, 120, 340.

(43) Lu, Y.; Tu, J.-p.; Gu, C.-d.; Xia, X.-h.; Wang, X.-l.; Mao, S. X. J. Mater. Chem. 2011, 21, 4843.

(44) Peng, S.; Lee, Y.; Wang, C.; Yin, H.; Dai, S.; Sun, S. Nano Res. 2008, 1, 229.

(45) Overbury, S. H.; Schwartz, V.; Mullins, D. R.; Yan, W.; Dai, S. J. Catal. 2006, 241, 56.

(46) Pina, C. D.; Falletta, E.; Rossi, M. Chem. Soc. Rev. 2012, 41, 350.

(47) Choudhary, V. R.; Dumbre, D. K. Top. Catal. 2oo9, 52, 1677.

(48) Zanella, R.; Giorgio, S.; Henry, C. R.; Louis, C. J. Phys. Chem. B 2002, 106, 7634 .

(49) Fu, Q.; Saltsburg, H.; Flytzani-Stephanopoulos, M. Science 2003, 301, 935 .

(50) Haruta, M.; Tsubota, S.; Kobayashi, T.; Kageyama, H.; Genet, M. J.; Delmon, B. J. Catal. 1993, 144, 175.

\section{Table of Content Graphic}

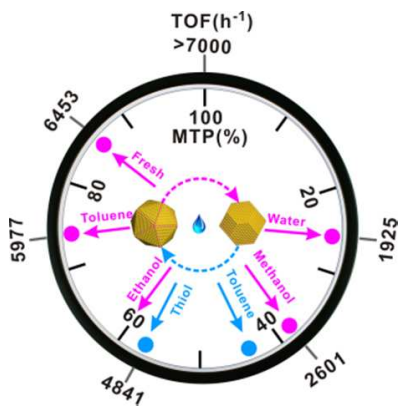



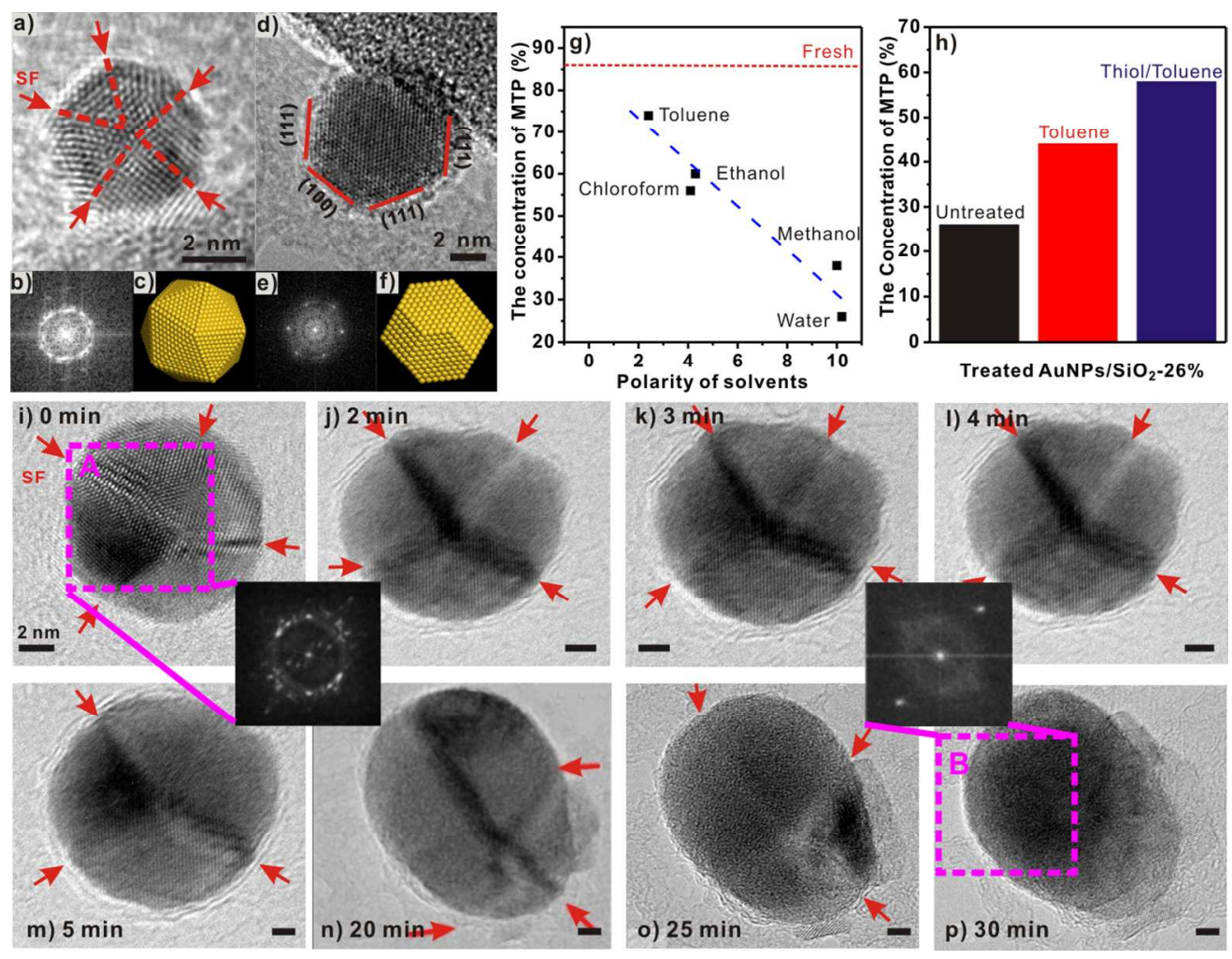

I) 4 min
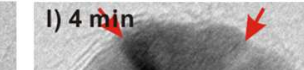

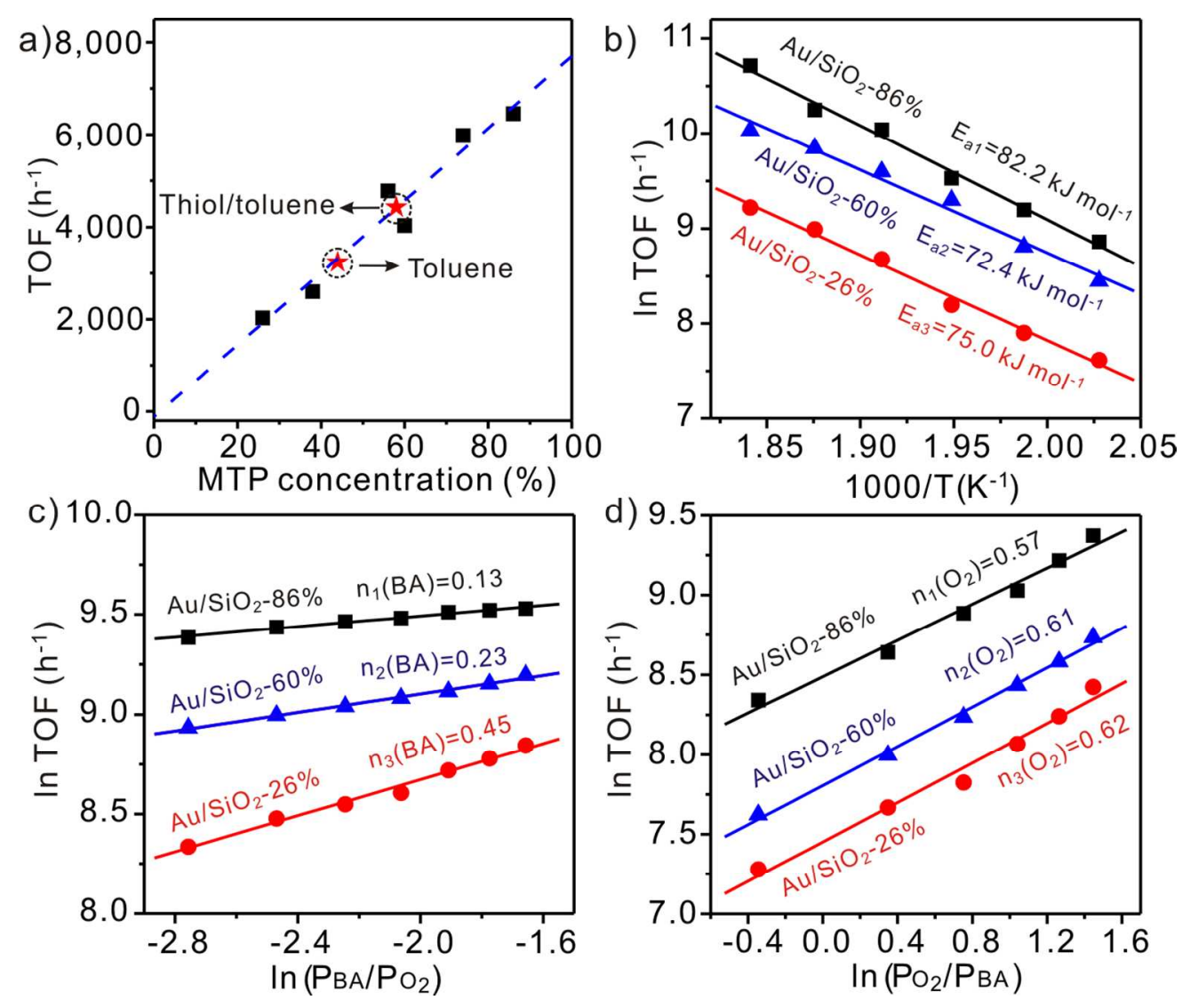

$119 \times 101 \mathrm{~mm}(300 \times 300$ DPI $)$ 

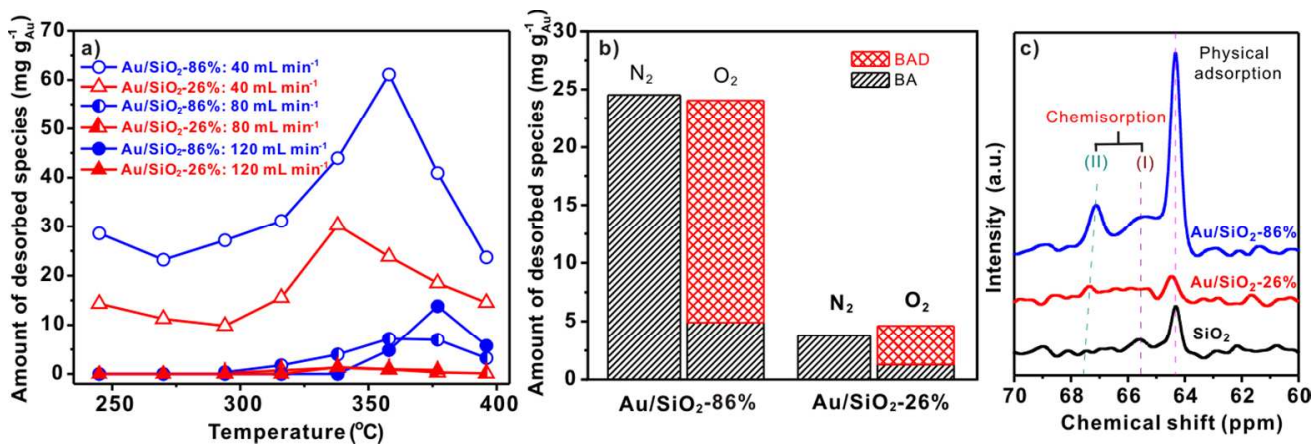

$119 \times 39 m m(300 \times 300$ DPI $)$ 


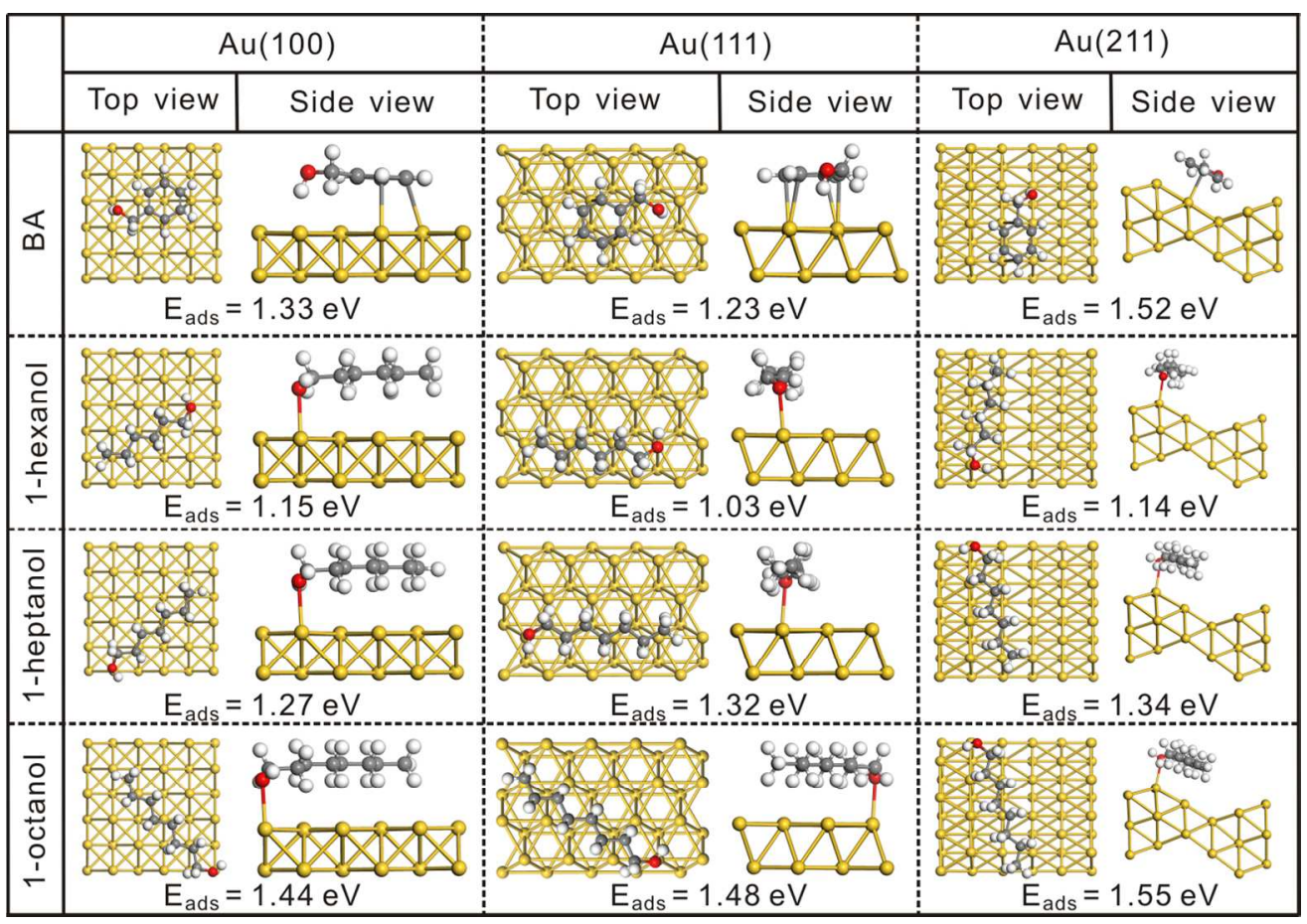

$119 \times 83 \mathrm{~mm}(300 \times 300 \mathrm{DPI})$ 


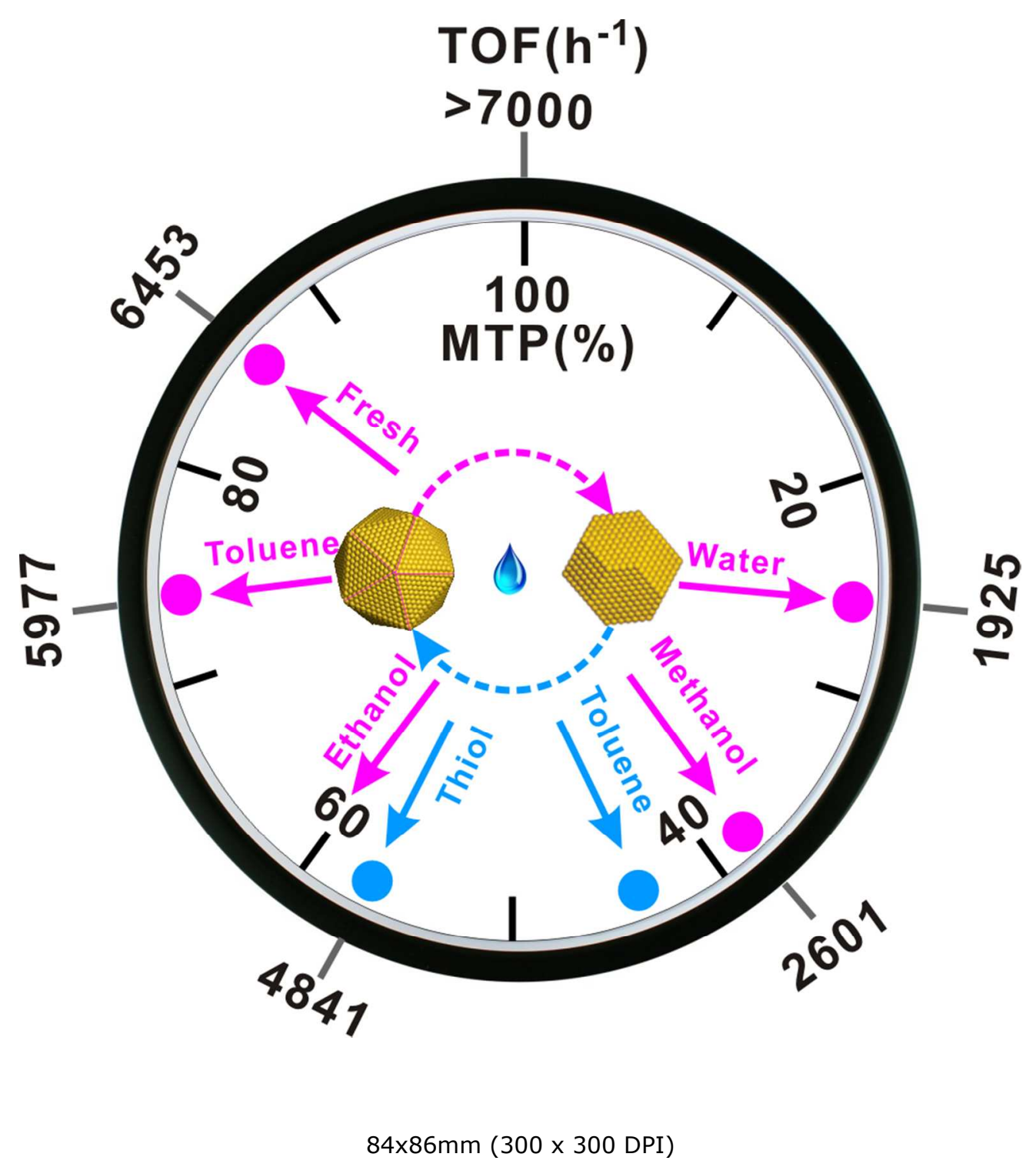

